East African Medical Journal Vol. 80 No. 10 October 2003

BLOOD PRESSURE CONTROL IN A POPULATION WHERE ANTIHYPERTENSIVES ARE GIVEN FREE

B. L. Salako MBBS, FWACP, Department of Medicine, College of Medicine, University of Ibadan, University College Hospital, Ibadan, PMB 5116, Ibadan,

Nigeria, F. A. Ajose, MBBS, MRCP and E. Lawani, MBBS, FWACP, Medical Unit International Institute for Tropical Agriculture, Ibadan, Osun State, Nigeria

Request for reprints to: Dr. B. L. Salako, Department of Medicine, University of Ibadan, University College Hospital, Ibadan, PMB 5116, Ibadan, Nigeria

\title{
BLOOD PRESSURE CONTROL IN A POPULATION WHERE ANTIHYPERTENSIVES ARE GIVEN FREE
}

\author{
B. L. SALAKO, F. A. AJOSE and E. LAWANI
}

\begin{abstract}
Background: Analysis of blood pressure control has shown that optimal blood pressure control is generally low in many studies. Poor adherence to therapeutic plans and noncompliance are perhaps the most important factors responsible for poor control. In most cases poverty has been adduced to be responsible for non-compliance especially in the sub-Saharan Africa. Assessment of blood pressure control in situations where antihypertensives are given free is necessary.

Objectives: To assess blood pressure control in a population where antihypertensives are given free.

Setting: International institute for tropical Agriculture (IITA).

Design: Cross-sectional study.

Subjects: One hundred and forty three consecutive hypertensive subjects (106 males and 37 females) being followed-up in the medical clinic of the International Institute for Tropical Agriculture (IITA) for variable numbers of years were studied. Blood pressure was considered to be well controlled if it was less than $140 / 90 \mathrm{mmHg}$ and uncontrolled if higher than $140 / 90 \mathrm{mmHg}$.

Results: About 51(36\%) of the subjects may be described as being fully controlled on the treatment instituted while $54(38 \%)$ of the subjects were not controlled at all. In about $18 \%$ of the patients, the systolic blood pressure alone was controlled while in 8\% the diastolic blood pressure alone was controlled.

Main Outcome measures: Level of blood pressure control in this study is poor suggesting that availability of free drug alone is not enough to improve adherence to antihypertensives.

Conclusion: The percentage of hypertensive patients with optimal blood pressure control in this population is low, although this was higher when compared to a report from a similar study where drugs were not given free to patients. Physicians managing hypertension in such establishments should pay attention to adequate dosing and appropriate combination of drugs.
\end{abstract}

\section{INTRODUCTION}

Uncontrolled hypertension remains a major threat to global health. It is a major cause of morbidity and mortality, and a leading cause of stroke, heart and kidney disease even in the developed world $(1,2)$. Analysis of levels of blood pressure control has shown that optimal blood pressure control ranged between $21 \%$ and $53 \%$ in some studies (3). These figures were mostly from studies where patients procure drugs by themselves. Non-compliance and poor adherence to therapeutic plans are perhaps the most important factors responsible for poor blood pressure control (4). In most cases poverty has been adduced to be responsible for non-compliance, especially in the sub-Saharan Africa. Assessment of blood pressure control in situations where anti-hypertensive drugs are made available to subjects by their employers is therefore desirable. The
International Institute for Tropical Agriculture (IITA) is appropriate for this type of study as it has a standard medical department where hypertensive subjects are followed up regularly and all anti-hypertensives prescribed are made available to subjects without payment at collection point. In this study we set out to assess the control of blood pressure among hypertensive subjects where procurement and cost of drug did not constitute a problem, using the IITA hypertensive population. We hope this will serve as useful information on control of blood pressure in such a setting.

\section{MATERIALS AND METHODS}

The study consists of 143 consecutive primary hypertensive subjects (106 males and 37 females) being followed-up in the medical clinic of the IITA for variable numbers of years. After informed consent was obtained from the subjects, 
patients' blood pressures were taken in sitting position by the same group of people in the clinic, usually in the morning. Recruitment into the study was spread over a period of 12 weeks. Blood pressure was measured in the subjects after 5 minutes of rest and an average of two measurements taken. A standard mercury sphygmomanometer was used and systolic blood pressure (SBP) and diastolic blood pressure (DBP) were taken as Korotkoff sound phases I and V respectively. An appropriate cuff size was applied to the exposed right upper arm and was rapidly inflated to $30 \mathrm{mmHg}$ above the level at which the pulse disappeared and then deflated gradually. Blood pressure was considered to be well controlled if it was less than $140 / 90 \mathrm{mmHg}$ and uncontrolled if higher than $140 / 90 \mathrm{mmHg}$. Other data were collected using a structured questionnaire to obtain relevant information on age, gender, compliance, length of treatment, drugs taken for the control of blood pressure and salt intake. Mantel-Haenszel chi squared test was used to assess the differences between categories of patients and significance was reached at $\mathrm{P}<00.05$.

\section{RESULTS}

One hundred and forty three consecutive hypertensive patients were assessed, consisting of 106 males and 37 females. The mean age of the group as a whole was $46.35 \pm 8.64$ years, while the mean ages of the male and female sub-groups were $47.64 \pm 8.63$ years and $43.77 \pm 8.65$ years respectively. There were 135 Nigerians, five Caucasians, two Ghanaians and one subject from the Sierra Leone. Diuretics, mainly thiazide were prescribed in 90(63\%) of the subjects, betablockers $24(17 \%)$, centrally acting agent mainly alpha- methyldopa $16(11 \%)$, calcium channel blockers $9(6.3 \%)$, angiotensin converting enzyme inhibitors five $(3.5 \%)$ and alpha-blocker in one $(0.7 \%)$. More than $90 \%$ of the patients claimed that they had been regular on their anti-hypertensive drugs and up to $90 \%$ admitted to using sodium containing food additives.

Table 1 represents the pattern of blood pressure control in the subjects. About 51(36\%) of the subjects may be described as being fully controlled on the treatment instituted while $54(38 \%)$ of the subjects were not controlled at all. In about $18 \%$ of the patients, the systolic blood pressure alone was controlled while in $8 \%$ the diastolic blood pressure alone was controlled.

Table 1

Pattern of blood pressure control

\begin{tabular}{lccc}
\hline \multicolumn{1}{c}{ Male (\%) } & Female (\%) & Total(\%) \\
\hline Fully controlled & $38(35.8)$ & $13(35.1)$ & $51(36)$ \\
Fully Uncontrolled & $41(38.7)$ & $13(5.1)$ & $54(38)$ \\
Only SBP controlled & $20(18.9)$ & $6(16.3)$ & $6(16.3)$ \\
Only DBP controlled & $7(6.6)$ & $5(13.5)$ & $12(8)$ \\
\hline & 143 & 106 & 37 \\
\hline
\end{tabular}

Table 2

Mean age and blood pressure of all subjects

\begin{tabular}{|c|c|c|c|c|c|c|}
\hline & Male & $\begin{array}{l}\text { Age in years } \\
\text { Female }\end{array}$ & Total & $\begin{array}{l}\text { Blood pressure } \\
\text { Male }\end{array}$ & $\begin{array}{l}\text { in } \mathrm{mmHg} \\
\text { Female }\end{array}$ & Total \\
\hline \multirow{2}{*}{$\begin{array}{l}\text { Fully Controlled } \\
\mathrm{n}=51\end{array}$} & $46.64 \pm 9.7$ & $40.1 \pm 7.82$ & $43.37 \pm 8.76$ & $120.47 \pm 20$ & $113.53 \pm 25$ & $115.84 \pm 22$ \\
\hline & & & & $79.63 \pm 3.14$ & $78.85 \pm 4.16$ & $79.24 \pm 0.55$ \\
\hline \multirow{2}{*}{$\begin{array}{l}\text { Fully Uncontrolled } \\
\mathrm{n}=54\end{array}$} & $49.52 \pm 7.81$ & $47.64 \pm 8.92$ & $48.58 \pm 8.35$ & $151.75 \pm 11.52$ & $151.87 \pm$ & $151.81 \pm 11.2$ \\
\hline & & & & $98.45 \pm 9.44$ & $95.35 \pm 7.45$ & $96.9 \pm 8.45$ \\
\hline $\begin{array}{l}\text { Only SBP Controlled } \\
n=26\end{array}$ & $46.55 \pm 81$ & $38.33 \pm 15.65$ & $42.44 \pm 11.88$ & $113.82 \pm 34$ & $103.3 \pm 52$ & $108.56 \pm 43$ \\
\hline $\begin{array}{l}\text { Only DBP Controlled } \\
\mathrm{n}=12\end{array}$ & $50.83 \pm 8.25$ & $46.6 \pm 13.3$ & $48.72 \pm 10.78$ & $82.14 \pm 2.67$ & $82 \pm 2.7$ & $82 \pm 2.7$ \\
\hline
\end{tabular}


Table 3

Number of drugs per patient

\begin{tabular}{lccr}
\hline No. of drugs & Male $(\%)$ & Female $(\%)$ & Total $(\%)$ \\
\hline 1 & $81(73)$ & $30(27)$ & $111(77.6)$ \\
2 & $23(82)$ & $5(17.8)$ & $28(19.6)$ \\
3 & $2(50)$ & $2(50)$ & $4(2.8)$ \\
\hline & 106 & 37 & $143(100)$ \\
\hline
\end{tabular}

Table 2 shows the mean age and blood pressure levels of the subjects. The mean age of subjects that were fully controlled was significantly lower than those that were not controlled $\mathrm{P}<0.001$, when analysed by gender, this same pattern persisted $\mathrm{P}<0.02$ (female group), but did not reach significance in the male group.

Table 3 describes the number of drugs per patient. $77.6 \%$ were on only one drug treatment most of which were fixed dose combination drugs, while $22.4 \%$ were on more than one drug. No subject was on more than three drugs.

\section{DISCUSSION}

Majority of our study population, were in the middle age with a strong male preponderance. This perhaps, only reflects the population/gender distribution of the workers in IITA as previous reports have found female preponderance in keeping with the notion that hypertension is more common in females in middle age $(3,5)$. Whereas some studies have noted that younger hypertensive patients are more likely to miss there medications leading to poor control(6,7), our findings here suggest otherwise, as the mean age of patients who were fully controlled in this study was significantly lower than those that were not controlled at all.

The overall rate of controlled hypertension in this study was $36 \%$, while $38 \%$ were fully uncontrolled. Looking at the blood pressure levels among those with good control women appeared to show more response to treatment than men, perhaps because women are more likely to adhere to therapeutic plan(7). Although not directly comparable, when the IITA control rate is compared with the figure documented at the MOP clinic of the University College Hospital, Ibadan (UCH), (25.4\%)(8) where patients have to buy their drugs, more IITA subjects appeared to achieve optimal control, however, both percentages were rather low. Seventy seven per cent of the subjects were on only one drug regime, while less than $25 \%$ were on two or more drugs. In most cases majority of hypertensive subjects will require more than one drug treatment to achieve optimal blood pressure control. It is also possible that the percentage of those controlled in this study would have been higher if more subjects have been placed on more than one drug. Thus, inadequate doses of anti-hypertensives perhaps arising from hesitance towards the use of more than one drug on the part of the physicians may have contributed significantly to the low level of optimal control of blood pressure in this population.

Majority of the subjects claimed they were compliant to therapy, while some admitted to missing their drugs. It is often said that between $16 \%$ and $50 \%$ of newly diagnosed hypertensives discontinue their anti-hypertensive medications during the first year and a substantial proportion of those who remain on therapy will routinely miss medication doses(9). Poor compliance to non-drug therapy was also noted as a factor responsible for poor control in this population. Many of the subjects admitted to no life style modification techniques. Inadequate dosages of antihypertensives and dietary indiscretion, especially liberal use of salt noted in this study have also been documented in the past. The most frequently used anti-hypertensive agents in this population include diuretics, beta-blockers and $\alpha$ methyldopa in that order. When compared to the UCH study, beta-blockers replaced calcium blockers. This may be due to physician's preference for certain drugs especially when the particular drugs are available.

ln conclusion, the percentage of hypertensive patients with optimal blood pressure control in the population study is low, although this was higher when compared to reports from similar studies done at $\mathrm{UCH}$, where drugs were not given free to patients. In spite of free drugs, non-compliance still existed in some of the patients suggesting that availability of free drug alone is not enough to improve adherence to anti-hypertensives.

Physicians managing hypertension in such establishments should therefore pay attention to adequate dosing and appropriate combination of drugs.

\section{REFERENCES}

1. Osuntokun B.O., Bademosi O., and Akinkugbe O.O. Incidence of stroke in an African City; Results from the stroke registry at Ibadan. Stroke. 1979; 10: 205-207.

2. Murray C.J.L. and Lopez A.D. Global mortality, disability and the contribution of risk factors: global burden of disease study. Lancet. 1997a; 349: 1436-1442.

3. Hussain A.A., Elzubier A.G., and Ahmed K.M-EIbagir. Target organ involvement in hypertensive patients in Eastern Sudan. $J$. Hum. Hypertens. 1999; 13: 9-12.

4. Guidelines for management of hypertension. Hypertension. 1999; 17: $153-183$

5. National Expert Committee on Non-Communicable diseases. NonCommunicable Diseases in Nigeria. Final report of a national survey. Fed. Min. of Health and Social services. Lagos, 1997.

6. O'Brain Smith E., Curb J.D., Handy K.J., et al., Clinic attendance in the hypertension detection and follow-up program. Hypertension.1982; 4: 710-715.

7. Degoulet P., Menard J., and Va H.A., Factors predicting attendance at clinic and blood pressure control in hypertensive patients. Brit. Med. J. 1983; 287: 88-89.

8. Salako B.L., Ayodele O.E., Kadiri S., and Arije A., Assessment of blood pressure control in a Black African population. Trop. Cardiol. 2002; 28: 3-6.

9. Haynes R.B. Management of compliance in the treatment of hypertension. Report of the NHLBI. Working Group. Hypertension 1982; 4:415-423. 